\title{
A relação do aumento de casos do Novo Coronavírus com a falta de Políticas Públicas de saneamento básico nas capitais das regiões Sul e Norte do Brasil
}

\author{
The relationship between the increase in cases of the New Coronavirus and the lack of Public Basic \\ sanitation policies in the capitals of the Southern and Northern regions of Brazil \\ La relación entre el aumento de casos del Nuevo Coronavirus y la falta de Políticas Públicas de \\ saneamiento básico en las capitales de las regiones Sur y Norte de Brasil
}

Recebido: 07/01/2021 | Revisado: 08/01/2021 | Aceito: 30/01/2021 | Publicado: 07/02/2021

\author{
Josivaldo Alves da Silva \\ ORCID: https://orcid.org/0000-0002-8160-4011 \\ Universidade Estadual do Tocantins, Brasil \\ E-mail: josivaldoadm@yahoo.com.br \\ Samanda Araújo Serpa \\ ORCID: http://orcid.org/0000-0003-0306-5531 \\ Universidade Federal do Tocantins, Brasil \\ E-mail: samanda.serpa@gmail.com \\ Viviane Araújo Leal \\ ORCID: https://orcid.org/0000-0002-3987-2899 \\ Universidade Federal do Tocantins, Brasil \\ E-mail: viviane.leal@mail.uft.edu.br
}

\begin{abstract}
Resumo
O debate sobre o aumento de casos de pessoas infectadas pelo novo coronavírus e sua relação com a falta de políticas públicas de saneamento básico, tem gerado questionamentos da comunidade acadêmica aos cientistas estudiosas dessa problemática. O objetivo deste artigo consiste em analisar a relação das incidências de casos de pessoas infectadas pelo novo coronavírus no período de 15 de março a 30 de junho de 2020 , com a falta de políticas públicas de saneamento básico nas capitais das regiões Sul e Norte do Brasil. A pesquisa é classificada como bibliográfica, descritiva, e de caráter exploratória, realizada através da busca na base de dados do IBGE, e nos Sites das Secretarias de saúde das Capitais da Região Norte e Sul do Brasil e portais de notícias. O método empregado foi o qualitativo e quantitativo, além de uma análise de conteúdo. $\mathrm{Na}$ análise constatou-se que, nas cidades que contam com a maior cobertura da coleta de esgoto e abastecimento de água tratada, apresentaram a menores taxas de incidências de pessoas infectadas pela Convid-19 por 100 mil habitantes.
\end{abstract}

Palavras-chave: Políticas públicas; Saneamento básico; Coronavírus; Covid-19.

\begin{abstract}
The debate about the increase in cases of people infected by the new coronavirus and its relationship with the lack of public basic sanitation policies, has raised questions from the academic community to scientists studying this problem. The objective of this article is to analyze the relationship between the incidence of cases of people infected with the new coronavirus from March 15 to June 30, 2020, with the lack of public basic sanitation policies in the capitals of the southern and northern regions of Brazil. . The research is classified as bibliographic, descriptive, and exploratory in nature, carried out by searching the IBGE database, and on the websites of the Health Secretariats of the Capitals of the North and South of Brazil and news portals. The method employed was qualitative and quantitative, in addition to content analysis. In the analysis it was found that, in cities that have the highest coverage of sewage collection and treated water supply, they had the lowest incidence rates of people infected by Convid-19 per (100 thousand inhabitants).
\end{abstract}

Keywords: Public policy; Basic sanitation; Coronavirus; Covid-19.

\section{Resumen}

El debate sobre el aumento de casos de personas infectadas por el nuevo coronavirus y su relación con la falta de políticas públicas de saneamiento básico, ha planteado interrogantes desde la comunidad académica a los científicos que estudian este problema. El objetivo de este artículo es analizar la relación entre la incidencia de casos de personas infectadas por el nuevo coronavirus del 15 de marzo al 30 de junio de 2020, con la falta de políticas públicas de saneamiento básico en las capitales de las regiones sur y norte de Brasil. La investigación se clasifica en carácter 
bibliográfico, descriptivo y exploratorio, realizada mediante búsquedas en la base de datos del IBGE, y en los sitios web de las Secretarías de Salud de las Capitales del Norte y Sur de Brasil y portales de noticias. El método empleado fue cualitativo y cuantitativo, además del análisis de contenido. En el análisis se encontró que, en las ciudades que tienen la mayor cobertura de recolección de aguas residuales y suministro de agua tratada, tenían las tasas de incidencia más bajas de personas infectadas por Convid-19 por cada 100 mil habitantes.

Palabras clave: Políticas públicas; Saneamiento básico; Coronavirus; Covid-19.

\section{Introdução}

Em termos conceituais, a definição de políticas públicas são processos que iniciam a partir da identificação de um problema público e delineado com a formação de uma agenda de prioridades, formulação de alternativas, tomada de decisões, implementação e avaliação que envolve diversos grupos que compõem a sociedade, cujos objetivos podem ser divergentes ou convergentes e tomam deliberações coletivas, que condicionam o conjunto de medidas que são transformadas em ações governamentais para atender demandas de interesse público. Quando essas decisões são tomadas coletivamente elas se convertem em algo a ser compartilhado, isto é em uma política comum (Rodrigues, 2010).

Dessa forma, pode-se deduzir que políticas públicas é o resultado de um conjunto de decisões que resultam em programas, projetos e ações direcionadas para assegurar as pessoas o direito o acesso aos serviços públicos essenciais resguardados na Constituição Federal, tais como, abastecimento de água, esgotamento sanitário, limpeza urbana, drenagem, manejos de resíduos sólidos e de águas pluviais.

Nesse sentido, o artigo $6^{\circ}$ da Constituição Federal de 1988, estabelece como direitos sociais fundamentais, o acesso à educação, a saúde, o trabalho, a moradia, o lazer, a segurança, a previdência social, a proteção à maternidade e à infância, a assistência aos desamparados (Constituição (1988). Dessa forma, o saneamento básico é um serviço público que contribui para o controle de vetores, doenças e preservação do meio ambiente, sendo de fundamental importância para a qualidade de vida das pessoas.

No Brasil, alguns estudos têm mostrado que a ausência de políticas públicas que garante o acesso universal das pessoas a água potável, coleta e tratamento de esgoto, pode-se tornar em um ambiente propício para o desenvolvimento e multiplicação de epidemias fácies de serem reproduzidas em humanos. Nesse aspecto, pode-se deduzir que, a algumas doenças se desenvolvem devido à água contaminada por falta de saneamento básico. Assim sendo, é de fundamental importância a realização de trabalhos científicos para averiguar a relação das incidências de casos de pessoas infectadas pelo novo coronavírus com a falta de políticas públicas de saneamento básico nas capitais das regiões sul e norte do Brasil.

Dessa forma, pesquisa nesta temática poderá servir como referência para que pesquisadores, gestores públicos e consultores que atuam nos demais municípios das Regiões sul e norte do Brasil, possam investigar com maior profundidade os fatores que contribuem para o aumento das incidências de casos do novo coronavírus. Entre os vários estudiosos da área de políticas públicas de saneamento básico no Brasil, podem-se destacar tais como, Borja (2004); Borja (2014), cuja análise estimulou uma série de estudos nesta ceara, porém, nenhum destes foi produzido objetivando analisar a relação das incidências de casos de pessoas infectadas pelo novo coronavírus com a falta de saneamento básico.

Posto isto, o objetivo deste trabalho é analisar a relação das incidências de casos de pessoas infectadas pelo novo coronavírus no período de 15 de março a 30 de junho de 2020, com a falta de políticas públicas de saneamento básico nas capitais das regiões sul e norte do Brasil. Identificar as opiniões de especialistas publicadas nos principais portais de notícias brasileiros sobre as possíveis causas da proliferação do coronavírus no brasil.

Diante do exposto, levanta-se o seguinte questionamento: quais os fatores que podem contribuir para a proliferação do coronavírus nas capitais das regiões sul e norte do Brasil? Este artigo está estruturado na seguinte ordem: a primeira parte aborda os fundamentos teóricos e conceituais relacionados às políticas públicas, a segunda, trata-se dos aspectos inerentes os 
conceitos e definições de saneamento básico, políticas públicas de saneamento básico e Coronavírus, Covid-19, fechando a parte conceitual para posteriormente, expor a metodologia, resultados, discussão dos resultados e as considerações finais.

\subsection{Políticas públicas}

As políticas públicas governamentais formuladas e implementadas de forma estratégica, pode-se tornar em um instrumento de gestão de fundamental importância para o alcance do desenvolvimento social e humano de uma população beneficiária, quando estabelecidos por ações resultantes da atividade política e participação direta dos atores interessados nas decisões políticas. Diante do exposto, pode-se afirmar que, não existe uma única definição sobre o que seja política pública. Nesse aspecto, os pressupostos teóricos adotados como conceitos de políticas públicas sustentadas neste artigo, estão diretamente ligados a um processo de discussão que envolve o estado e a sociedade, em que os objetivos são divergentes ou convergentes.

De acordo com a concepção de Teixeira (2002; 2014), as políticas públicas são diretrizes e princípios norteadores das ações, das regras e dos procedimentos para as relações do poder público e a sociedade, são mediações entre os atores da sociedade e do Estado. Essas políticas são explicitadas, sistematizadas em documentos, leis, programas e linhas de funcionamento que orientam as ações que envolvem a aplicação de recursos públicos.

Assim sendo, políticas públicas são um conjunto de decisões que visam a ações preventivas ou corretivas, destinadas a manter ou modificar setores da sociedade, através de formulação de objetivos e estratégias de atuação e da alocação dos recursos necessários para atingir os resultados estabelecidos (Saraiva \& Ferrarezi, 2006).

Nesse sentido, Aguilar (2012) afirma que podem ser denominadas de políticas públicas, as ações do governo cujo objetivo é alcançar o interesse público de forma eficaz e até eficiente. Essas ações do governo têm dupla dimensão, política e técnica, um componente normativo e científico-técnico. A dimensão política, são ações políticas, orientadas para realizar objetivos de interesse e benefício social geral, de acordo com os requisitos constitucionais-legais. A dimensão técnica, ações baseadas em raciocínio técnico causal, a de modo de alcançar os objetivos desejados, e a transformação das intenções dos governantes fatos sociais. O componente político e o técnico de política pública articulam-se bem, quando as ações são decididas pelo governo e tem aceitação social suficiente e produz os resultados esperados.

De fato, as políticas públicas são um processo dinâmico que envolve a vontade política é a utilização do aparelhamento do estado, dando ênfase nos procedimentos-meios para o alcance dos resultados-fins, para assim atender as demandas do cidadão-usuário de um determinado serviço de utilidade pública.

Em outras palavras, Rodrigues (2010) define políticas públicas como um processo pelo qual os diversos grupos que compõem a sociedade - cujos interesses, valores e objetivos são divergentes e tomam decisões coletivas, que condicionam o conjunto de decisões de interesse da coletividade. Quando as decisões coletivas são tomadas elas se convertem em algo a ser compartilhado.

Diante desta definição, pode-se afirmar que, o processo de construção de uma política pública, gera repercussões nas relações envolvendo atores responsáveis pela dinâmica e a comunidade interessada que se inicia na identificação das demandas e termina na materialização dos objetivos propostos caso alcance os resultados esperados pelo público demandante.

Destarte, os atores envolvidos diretamente nas políticas públicas são indivíduos, grupos ou organizações que desempenham um papel na arena política, lugar onde acontecem as disputas, que envolvem os partidos políticos, os burocratas, os grupos de interesses, os movimentos sociais, a mídia, as organizações não governamentais, as empresas, as redes de políticas públicas (Secchi, 2013).

Dito de outro modo, Teixeira (2002) afirma que políticas públicas é processo dinâmico, que envolve negociações, pressões, discussões, alianças ou coalizões de interesses, fatores que compreendem a formação de uma agenda que pode 
refletir ou não os interesses dos setores majoritários da população, a depender do grau de mobilização da sociedade civil para se fazer ouvir e do grau de institucionalização de mecanismos que viabilizem a participação da comunidade interessada.

Diante dessas afirmações, pode-se inferir que esses mecanismos enfatizam o papel dos órgãos públicos como espaço da ação coletiva e de integração das atribuições dos agentes públicos, orientados pelas diretrizes estabelecidas pelos poderes, legislativo e executivo, a base da institucionalidade legal para a criação, implementação, execução e avaliação das políticas públicas. Esse fato proporciona às instituições participativas a inserção no processo de partilha de poder entre os organismos estatais e atores da sociedade civil, por meio da manifestação de padrões de comportamentos da sociedade.

Em outros termos, Rodrigues (2010) é enfática ao reafirma que políticas públicas são resultantes da atividade política, requerem varias ações estratégicas destinadas a estabelecer os objetivos desejados e envolvem mais de uma decisão política. Uma de suas características principais é que são constituídas de decisões e ações que estão revestidas da autoridade soberana do poder público.

Em resumo, as políticas públicas são medidas governamentais reguladas por leis, regras e sistematizadas em forma desenho de programas e projetos para distinguir o que o governo pretende fazer, para atender demandas da comunidade através de serviços públicos. Essas medidas envolvem vários atores e níveis de decisão, embora seja materializada através de decisões governamentais planejadas com objetivos a serem alcançados é de fundamental importância a participação da comunidade. Embora tenha impactos no curto prazo é de longo prazo, envolve processos subsequentes implica em um ciclo que gira em torno do planejamento, implementação, execução e avaliação.

\subsection{Saneamento básico no Brasil}

A necessidade de medidas corretivas e preventivas no sentido de minimizar e corrigir os possíveis agravos ao meio ambiente e a saúde por falta da destinação dos dejetos e escoamento da água de forma adequada, foi percebida nos meados dos anos de 1700, durante a Revolução Industrial na Inglaterra, provocados pelas aglomerações humanas, aliados a expansão da indústria. A adoção de medidas de tratamento do esgoto de forma planejada com a criação de estação de processamento surgiu de fato a partir de 1850, na França; Itália; Inglaterra; Bélgica e nos Estados Unidos (Rocha, 2016).

A história do saneamento básico no Brasil inicia-se no início do século XIX, com o aparecimento e formação das cidades, o abastecimento de água era feito através de coleta em bicas e fontes, nos povoados que então se formavam. A primeira obra de saneamento básico ocorreu 1561, no Estado do Rio de Janeiro, por iniciativa de Estácio de Sá, fundador a cidade do Rio de Janeiro, mandou construir um poço para abastecer a vila de água. Os primeiros sistemas de água encanada, construídos no Brasil ocorreram em São Paulo entre 1857 e 1877, Porto Alegre e no Rio de Janeiro no período de 1861 e 1876.

Nesse período, a prestação de serviços de saneamento ficava sob a responsabilidade de empresas estrangeiras. A partir de 1930, os municípios foram responsabilizados pelos serviços de saneamento e abastecimento de água. Na década de 1940, começou a comercialização dos serviços de saneamento, o surgimento das autarquias e mecanismos de financiamento, como medida concreta do governo federal, foi criado o DNOS - Departamento Nacional de Obras de Saneamento (INCT: etes-sustentaveis, 2020).

A década de 50 foi marcada pelo aumento do êxodo rural, adensando as zonas urbanas que induz a formação de periferias sem o devido planejamento urbano, gerando impactos ao meio ambiente. Em 1970, criou-se o Plano Nacional de Saneamento (PLANASA), que culminou com a criação das Companhias Estaduais de Saneamento Básico, instituía-se no Brasil pela primeira vez uma política nacional de saneamento (Rocha, 2016). Essa política permaneceu até a promulgação da nova Constituição Federal em 5 de outubro de 1988. 
A partir de 1988, a Constituição Federal assegura como um direito a população o acesso a um conjunto dos serviços públicos tais como, infraestrutura, abastecimento de água, esgotamento sanitário, limpeza e drenagem urbana, manejos de resíduos sólidos e de águas pluviais. Nesse aspecto, a definição de saneamento básico, trata-se de um conjunto de medidas governamentais que visa preservar ou modificar as condições do meio ambiente com a finalidade de prevenir doenças, promover a saúde, melhorar a qualidade de vida da população e facilitar a atividade econômica (Lei no 11.445/2007).

Nesse sentido, Rocha (2016) define o saneamento básico como a disponibilidade de água tratada para o uso no abastecimento público, preservação dos cursos d'água para uso múltiplos, tratamento de esgoto sanitário, em geral, remoção e tratamento do lixo e dos resíduos sólidos de forma adequada.

Em resumo, a pesar das garantias constitucionais previstas, cerca de 35 milhões de brasileiros ainda não possuem acesso à água tratada, culminado com a alta taxa de desperdício, para cada 100 litros de água tratada, 37\% não são consumidas . Além do mais, cerca de 50\% da população do Brasil tem acesso à coleta de esgoto, ou seja, mais de 100 milhões de brasileiros ainda não possuem acesso a este tipo de serviço (Trata Brasil, 2020).

\subsection{Políticas públicas de saneamento básico}

A Constituição Federal de 1988 estabelece no seu artigo 21, ser competência comum da União, dos estados, do Distrito Federal e dos municípios a promoção de programas de melhoria das condições de saneamento básico. A carta magna institui as diretrizes, para o desenvolvimento urbano, inclusive habitação, saneamento básico (Constituição (1988).

Como consequência, em 17 de julho de 2000, entra em vigor a Lei n 9.984 que dispõe sobre a criação da Agência Nacional de Águas e Saneamento Básico (ANA), entidade federal de implementação da Política Nacional de Recursos Hídricos, integrante do Sistema Nacional de Gerenciamento de Recursos Hídricos (Singreh) e responsável pela instituição de normas de referência para a regulação dos serviços públicos de saneamento básico (Lei nº 9.984, 2000).

Em 15 de fevereiro de 2007, entra em vigor a Lei $n^{\circ} 11.445$, que estabelece diretrizes nacionais para o saneamento básico no Brasil. Dessa forma, a partir da aprovação desta lei, as políticas públicas de saneamento básico no Brasil são definidas pelas diretrizes estabelecidas pelo Federal, determinando que a União elabore o Plano Nacional de Saneamento Básico e a partir disso, oriente as ações e investimentos do Governo Federal. O plano de saneamento básico é o instrumento indispensável da política pública de saneamento e obrigatório para a contratação ou concessão desses serviços. A política e o plano devem ser elaborados pelos municípios individualmente ou organizados em consórcio, e essa responsabilidade não pode ser delegada. O Plano, a ser revisado a cada quatro anos, deve ter os objetivos e metas nacionais e regionalizadas e ainda os programas e ações para o alcance dessas metas (Lei no $11.445 / 2007)$.

Em 15 de julho de 2020, entrou em vigor a Lei no 14.026, que atualiza o marco legal do saneamento básico e altera a Lei $n^{\circ}$ 9.984, de 17 de julho de 2000, para atribuir à Agência Nacional de Águas e Saneamento Básico (ANA) competência para editar normas de referência sobre o serviço de saneamento. O novo marco regulatório, estabelece que a ANA instituirá normas de referência para a regulação dos serviços públicos de saneamento básico por seus titulares e suas entidades reguladoras e fiscalizadoras, observadas as diretrizes para a função de regulação estabelecida na Lei $\mathrm{n}^{\circ} 11.445$, de 5 de janeiro de 2007.

Dessa forma, é importante ressaltar que, as políticas públicas de saneamento no Brasil são recentes, vêm experimentando, após a aprovação da Constituição Federal de 1988, com maior consistência a partir dos 2000, com a institucionalização de marcos regulatório, reestruturação institucional com a criação do Ministério das Cidades e da Secretaria Nacional de Águas e Saneamento básico, que permitiu maiores investimentos e financiamentos neste setor (Lei $\mathrm{n}^{\circ}$ 9.984/2000).

Em síntese, a Lei $n^{\circ}$ 11.445/2007 inaugurou um período na gestão dos serviços públicos de saneamento básico no País, tendo o planejamento assumido a posição central na condução e orientação da ação pública (Brasil, 2007). A atualização 
do marco legal do saneamento básico no Brasil, através da Lei nº 14.026/2020, cria novas expectativas para a universalização das políticas públicas de saneamento básico até 2033, com a previsão de mais de 17 milhões de novas ligações de água e aproximadamente 33 milhões de ligações de esgoto (Lei nº 14.026/2020).

\subsection{Coronavírus, Covid-19, SARSCoV-2}

De modo geral, coronavírus é uma problemática recente, ainda não dispõe de uma bibliografia que aborda a sua definição conceitual. De acordo com os estudos preliminares, os coronavírus compreendem aproximadamente 40 vírus que infectam diversas espécies animais, fazem parte de uma família denominada Coronaviridae.Trata-se de uma alusão à aparência desses vírus quando visualizados por microscopia eletrônica.

Dessa forma, os membros dessa família infectam mamíferos, aves e peixes, sendo alocados em quatro: Alphacoronavirus, Betacoronavirus, Gammacoronavirus e Deltacoronavirus. Os coronavírus possuem um genoma constituído por uma única cadeia de RNA envolto em algumas proteínas e uma camada externa chamada "envelope", derivada das membranas celulares (UFRGS, 2020).

Portanto, o Novo Coronavírus, Covid-19, pertencente a uma vasta família de vírus, que pode causar sintomas parecidos com os da gripe comum ou até casos mais graves. No Brasil, até janeiro de 2020, esse tipo de vírus não havia sido previamente identificado em seres humanos (Ministério da Saúde (2020).

\section{Metodologia}

A aplicação dos métodos de forma adequada é uma prerrogativa da ciência. Em termos práticos, o método é entendido como um conjunto de atividades racionais e sistemáticas que possibilitam alcançar o objetivo da pesquisa de modo seguro (Popper, 2008). Nesse aspecto, as decisões da escolha dos métodos de pesquisa devem ser relacionadas ao caráter dos dados trabalhados na investigação (Flick, 2013). Este trabalho, de caráter descritivo e exploratório, está inscrito no paradigma interpretativo.

Dessa forma, entende-se que ama das maneiras de se realizar a análise de significado é utilizando o paradigma interpretativo como estratégia metodológica possível de analisar o que as pessoas pensam sobre determinados objetos em contextos diferentes e de acordo com a sua concepção. A interpretação do significado da ação somente é possível quando se adquire conhecimento sobre os significados que sustentam as ações, compreendendo-se as teorias dos atores via evidências qualitativas (Alencar, 2002).

Partindo do já posto, a metodologia escolhida é essencialmente quantitativa, qualitativa e aplicação de análise de conteúdo realizada por intermédio de pesquisa bibliográfica. Uma vez que, o método, análise de conteúdo é conjunto de técnicas aplicadas na pesquisa visando obter, por procedimentos sistemáticos e objetivos de descrição do conteúdo das mensagens, que permitam a inferência de conhecimentos relativos às condições de produção e recepção (Bardin, 2010).

Para atender os métodos propostos, a operacionalização da pesquisa ocorreu em cinco momentos distintos. Os momentos de execução da pesquisa estão escritos na ordem proposta por Bardin (2010), em três etapas, iniciando pela organização, seleção das fontes de pesquisa, análise do material colhido; codificação dos termos, separação das frases e palavras chaves, relacionadas ao contexto; categorização de conceitos relacionados á políticas públicas, saneamento básico, frases que tenha relação das incidências de casos de pessoas infectadas pelo novo coronavírus com a falta de políticas públicas de saneamento básico nas capitais das regiões Sul e Norte do Brasil, uma abordagem teórico-empírica apresentação dos resultados. 
Inicialmente, foi realizada uma investigação de cunho bibliográfico, de forma a identificar a bibliografia e a legislação pertinente, elementos teóricos escolhidos para a construção da fundamentação dos aspectos históricos e conceituais que caracterizam as políticas públicas de saneamento básico Brasil.

No segundo momento, buscou-se na base de dados do Instituto Brasileiro de Geografia e Estatística (IBGE) a população estimada em 2020, das capitais escolhidas como objeto desta pesquisa. No terceiro plano, acessou-se o Site do Ministério do Desenvolvimento Regional, especificamente na base de dados do Sistema Nacional de Informações sobre Saneamento (SNIS), para assim identificar os índices de abastecimento água tratada, coleta e tratamento de esgoto nas capitais escolhidas como objeto deste estudo.

No quarto momento, realizaram-se buscas periódicas nos Sites das Secretarias municipais e estaduais de saúde para identificar os casos confirmados de Covid-19 nas Capitais da Região Norte e Sul do Brasil no período de março a junho 2020. No quinto e último momento, procedeu-se a busca nos sites dos portais de notícias Fiocruz; BandNews FM; BBC News Brasil; Portal Uol Notícias; CNN Brasil e Jornal da USP, de modo identificar a opinião de especialistas em entrevistados sobre as possíveis causas da proliferação do coronavírus no Brasil. Dito isto, a seguir serão apresentados os resultados.

\section{Resultados e Discussão}

Partindo das questões já apresentadas, procurou-se averiguar os resultados da relação das incidências de casos de pessoas infectadas pelo novo coronavírus, com a falta de políticas públicas de saneamento básico nas capitais das regiões Sul e Norte do Brasil. A partir das variáveis; cobertura do tratamento de esgoto é água tratada; categorização de conceitos relacionados á políticas públicas, saneamento básico através da análise de conteúdo de Bardin e opiniões de instituições e especialista sobre as possíveis causas de disseminação do novo coronavírus, Covid-19. Diante do exposto, a seguir serão apresentados os resultados das inferências e interpretações conforme a perspectiva de Bardin.

Quadro 1. Políticas públicas de saneamento básico no Brasil.

\begin{tabular}{|c|c|c|}
\hline Tipos de políticas públicas & Evidências textuais & Referencial teórico \\
\hline $\begin{array}{l}\text { Políticas públicas de Saneamento } \\
\text { Básico No Brasil. }\end{array}$ & $\begin{array}{l}\text { A carta magna institui as diretrizes, } \\
\text { para o desenvolvimento urbano, } \\
\text { inclusive habitação, saneamento } \\
\text { básico (Brasil, 1988). }\end{array}$ & $\begin{array}{l}\text { A Constituição Federal de } 1988 \text { estabelece } \\
\text { no seu artigo } 21 \text {, ser competência comum } \\
\text { da União, dos estados, do Distrito Federal e } \\
\text { dos municípios a promoção de programas } \\
\text { de melhoria das condições de saneamento } \\
\text { básico. }\end{array}$ \\
\hline $\begin{array}{l}\text { Programas de Saneamento Básico } \\
\text { No Brasil. }\end{array}$ & $\begin{array}{l}\text { A Lei } 11.445 \text {, estabelece diretrizes } \\
\text { nacionais para o saneamento básico } \\
\text { no Brasil. }\end{array}$ & $\begin{array}{l}\text { A partir da aprovação desta lei, as políticas } \\
\text { públicas de saneamento básico no Brasil } \\
\text { são definidas pelas diretrizes estabelecidas } \\
\text { pelo Federal, determinando que a União } \\
\text { elabore o Plano Nacional de Saneamento } \\
\text { Básico e a partir disso, oriente as ações e } \\
\text { investimentos do Governo Federal. }\end{array}$ \\
\hline $\begin{array}{l}\text { Programas de Saneamento Básico } \\
\text { No Brasil. }\end{array}$ & $\begin{array}{l}\text { Em } 15 \text { de julho de } 2020 \text {, entrou em } \\
\text { vigor a Lei } n^{\circ} 14.026 \text {, que atualiza o } \\
\text { marco legal do saneamento básico e } \\
\text { altera a Lei } n^{\circ} 9.984 \text {, de } 17 \text { de julho } \\
\text { de } 2000 \text {, para atribuir à Agência } \\
\text { Nacional de Águas e Saneamento } \\
\text { Básico (ANA) competência para } \\
\text { editar normas de referência sobre o } \\
\text { serviço de saneamento. }\end{array}$ & $\begin{array}{l}\text { O novo marco regulatório, estabelece que a } \\
\text { ANA instituirá normas de referência para a } \\
\text { regulação dos serviços públicos de } \\
\text { saneamento básico por seus titulares e suas } \\
\text { entidades reguladoras e fiscalizadoras, } \\
\text { observadas as diretrizes para a função de } \\
\text { regulação estabelecida na Lei } \mathrm{n}^{\circ} 11.445 \text {, de } \\
5 \text { de janeiro de } 2007 \text {. }\end{array}$ \\
\hline
\end{tabular}

Fonte: Análise de conteúdo em termos de Bardin (2010) categorização adaptado pelos autores. 
Quadro 2. Palavras-chave frases essenciais e cobertura saneamento básico de nas Capitais da Região Norte e Sul do Brasil.

\begin{tabular}{|l|l|l|}
\hline \multicolumn{1}{|c|}{ Palavra-chave } & \multicolumn{1}{|c|}{ Frases essenciais } & \multicolumn{1}{|c|}{ Categorização } \\
\hline Saneamento básico. & $\begin{array}{l}\text { O Ranking é fundamental para } \\
\text { revelar a lentidão que avança as } \\
\text { políticas públicas de saneamento no } \\
\text { Brasil. }\end{array}$ & Ranking do Saneamento no Brasil. \\
\hline Abastecimento água tratada. & $\begin{array}{l}\text { O fornecimento universal de água } \\
\text { trata contribui para a redução de } \\
\text { doenças epidêmicas. }\end{array}$ & $\begin{array}{l}\text { Fornecimento de água tratada nas capitais } \\
\text { da região Sul e Norte do Brasil. }\end{array}$ \\
\hline Coleta de esgoto. & $\begin{array}{l}\text { O fornecimento universal dos } \\
\text { serviços de coleta de esgoto } \\
\text { contribui para a redução de doenças } \\
\text { epidêmicas. }\end{array}$ & $\begin{array}{l}\text { Serviços de rede de coleta de esgoto nas } \\
\text { capitais da região Sul e Norte do Brasil. }\end{array}$ \\
\hline Tratamento de esgoto. & $\begin{array}{l}\text { O tratamento do esgoto sanitário } \\
\text { contribui para a redução de doenças } \\
\text { epidêmicas. }\end{array}$ & $\begin{array}{l}\text { Serviços de tratamento de esgoto nas } \\
\text { capitais da região Sul e Norte do Brasil. }\end{array}$ \\
\hline
\end{tabular}

Fonte: Análise de conteúdo em termos de Bardin (2010) categorização adaptado pelos autores.

Quadro 3. Palavra-chave, frases essenciais e casos confirmados de Covid-19 nas Capitais da Região Norte e Sul do Brasil de março a junho-2020.

\begin{tabular}{|l|l|l|}
\hline \multicolumn{1}{|c|}{ Palavra-chave } & \multicolumn{1}{|c|}{ Frases essenciais } & \multicolumn{1}{|c|}{ Categorização } \\
\hline Casos confirmados. & $\begin{array}{l}\text { O aumento de casos tem relação } \\
\text { com a falta de saneamento básico. } \\
\text { O aumento de casos não tem } \\
\text { relação com a falta de saneamento } \\
\text { básico. }\end{array}$ & Incidências de casos confirmados. \\
\hline
\end{tabular}

Fonte: Análise de conteúdo em termos de Bardin (2010) categorização adaptado pelos autores.

Quadro 4. Palavra-chave, frases essenciais e opiniões de especialistas sobre as possíveis causas da proliferação do coronavírus no Brasil.

\begin{tabular}{|l|l|l|}
\hline \multicolumn{1}{|c|}{ Palavra-chave } & \multicolumn{1}{|c|}{ Frases essenciais } & \multicolumn{1}{|c|}{ Categorização } \\
\hline $\begin{array}{l}\text { Possíveis causas da proliferação do } \\
\text { coronavírus no Brasil. }\end{array}$ & $\begin{array}{l}\text { A carência dos serviços de } \\
\text { saneamento básico pode deixar a } \\
\text { população vulnerável, fazendo com } \\
\text { que as pessoas adoeçam com mais } \\
\text { frequência. }\end{array}$ & $\begin{array}{l}\text { A falta de saneamento básico contribui } \\
\text { para propagação da Covid-19. }\end{array}$ \\
\hline $\begin{array}{l}\text { Precariedade do saneamento básico, } \\
\text { em Manaus. }\end{array}$ & $\begin{array}{l}\text { O alto número de casos de Covid- } \\
19 \text { no Amazonas pode ter relação } \\
\text { com a precariedade do saneamento } \\
\text { básico. }\end{array}$ & $\begin{array}{l}\text { A falta de saneamento básico contribui } \\
\text { Contaminação da Covid-19. }\end{array}$ \\
\hline $\begin{array}{l}\text { O vírus continua sendo secretado } \\
\text { pelas fezes mesmo após a pessoa ter } \\
\text { sido curada e mesmo em pessoas } \\
\text { que estão assintomáticas, porque } \\
\text { pode sim acontecer algo que é } \\
\text { chamado de contaminação fecal- } \\
\text { oral. }\end{array}$ & \begin{tabular}{l} 
A falta de saneamento básico contribui \\
\hline
\end{tabular} \\
\hline
\end{tabular}

Fonte: Análise de conteúdo em termos de Bardin (2010) categorização adaptado pelos autores. 
Diante da análise exposta, a seguir serão apresentados os resultados quantitativos da cobertura da coleta de esgoto e água tratada nas capitais das regiões Norte e Sul do Brasil.

Gráfico 1. População estimada das capitais das regiões Norte e Sul do Brasil.

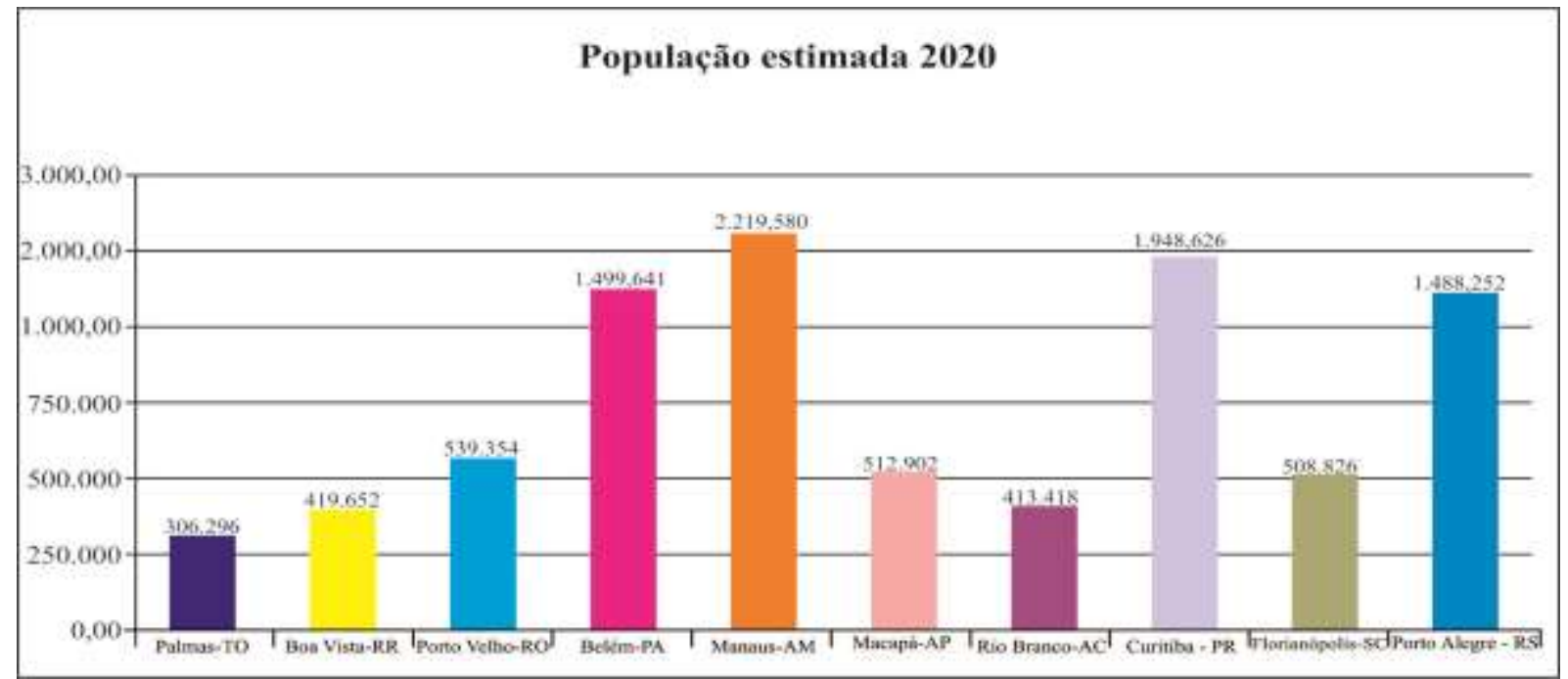

Fonte: IBGE (2020).

Gráfico 2. Cobertura da coleta de esgoto nas capitais das regiões Norte e Sul do Brasil.

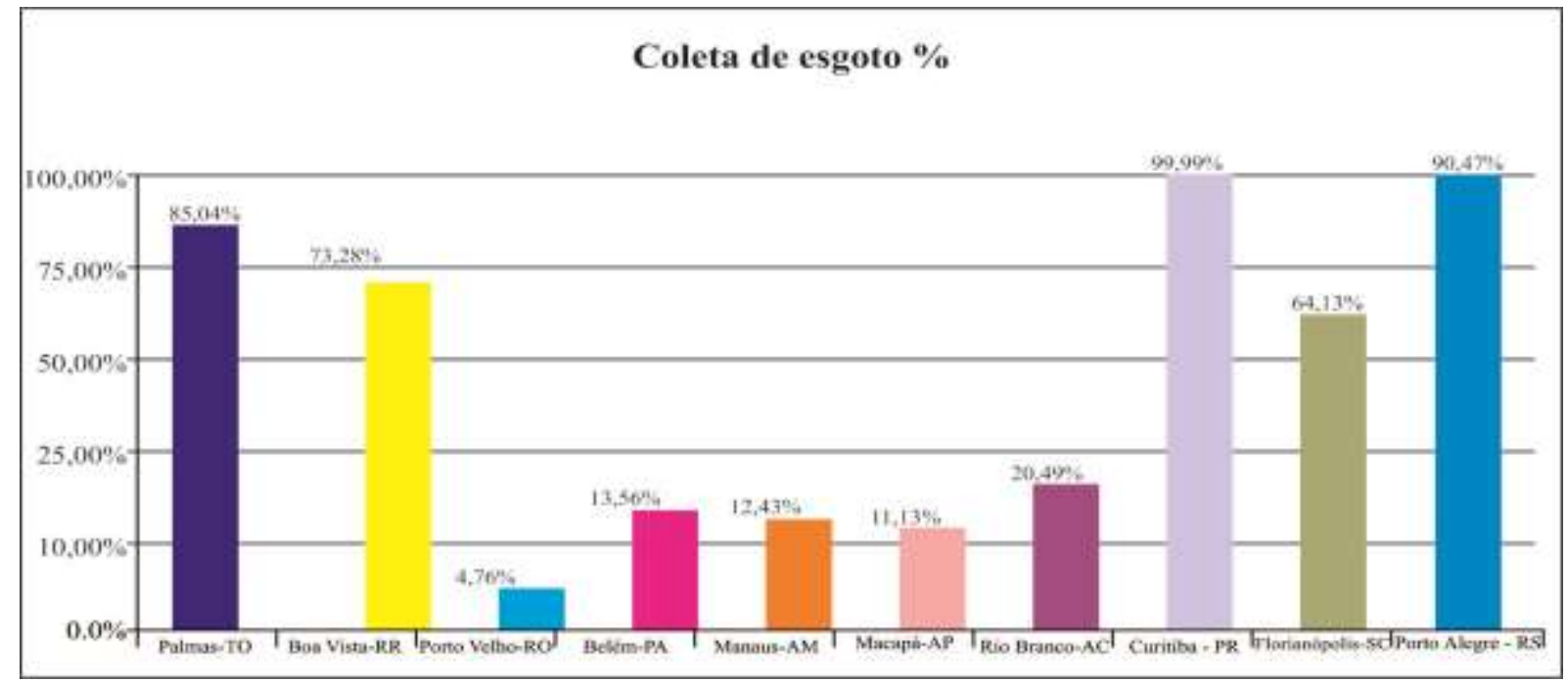

Fonte: Ministério do Desenvolvimento Regional - MDR (2020). Dados: SNIS (2018); Trata Brasil (2020).

De acordo com o gráfico acima, pode-se afirmar que no quesito coleta de esgoto, duas capitais da Região Norte, Palmas, Tocantins e Boa Vista, Roraima, apresentam os maiores índices de cobertura. Por outro lado, na Região Sul, três capitais, sendo Curitiba Paraná, Florianópolis, Santa Catarina, e Porto Alegre, Rio Grande do Sul, se destacam com a maior cobertura destes serviços públicos. 
Gráfico 3. Cobertura do tratamento de esgoto nas capitais das regiões Norte e Sul do Brasil.

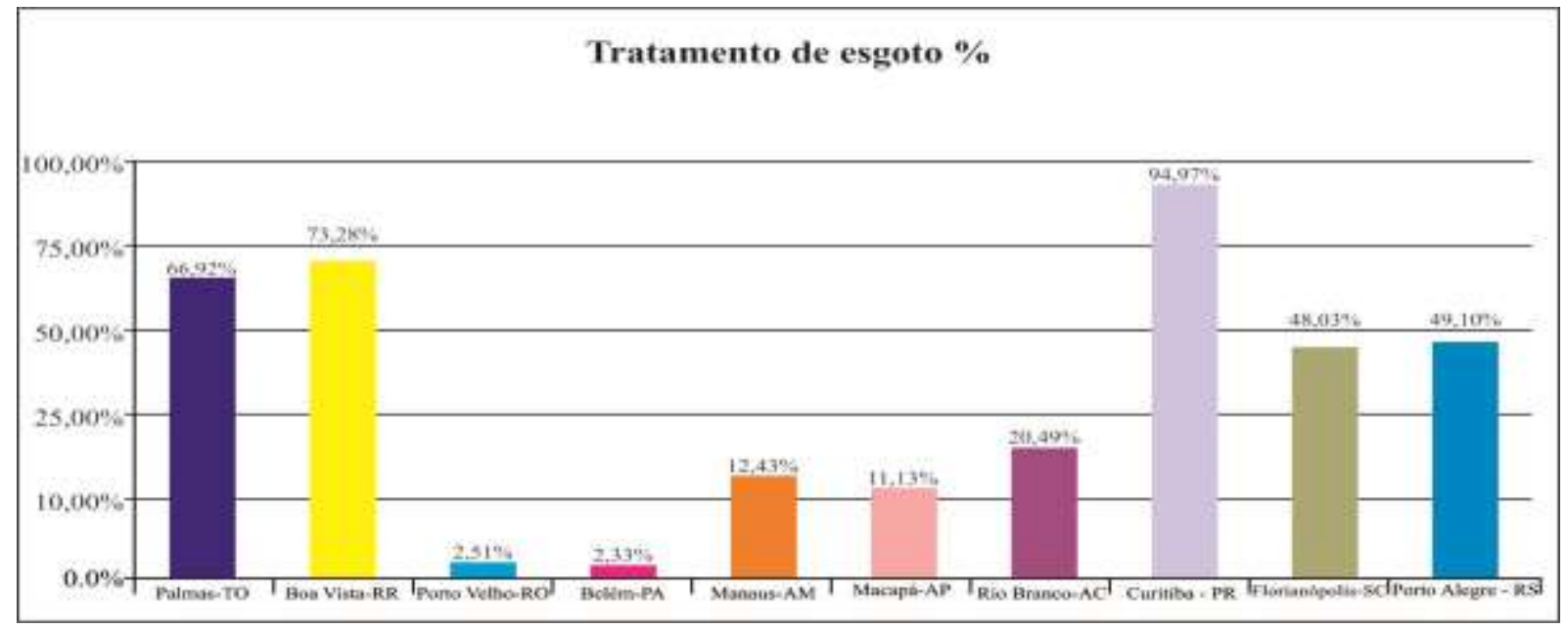

Fonte: Ministério do Desenvolvimento Regional - MDR (2020). Dados: SNIS (2018); Trata Brasil (2020).

Conforme evidencia o gráfico acima, pode-se inferir que no quesito tratamento de esgoto, as capitais da Região Norte, Palmas/TO e Boa Vista RR, apresentam os maiores índices, por outro lado, na Região Sul, Curitiba Paraná se destaca com a maior cobertura destes serviços públicos.

Gráfico 4. Cobertura do abastecimento de água tratada nas capitais das regiões Norte e Sul do Brasil.

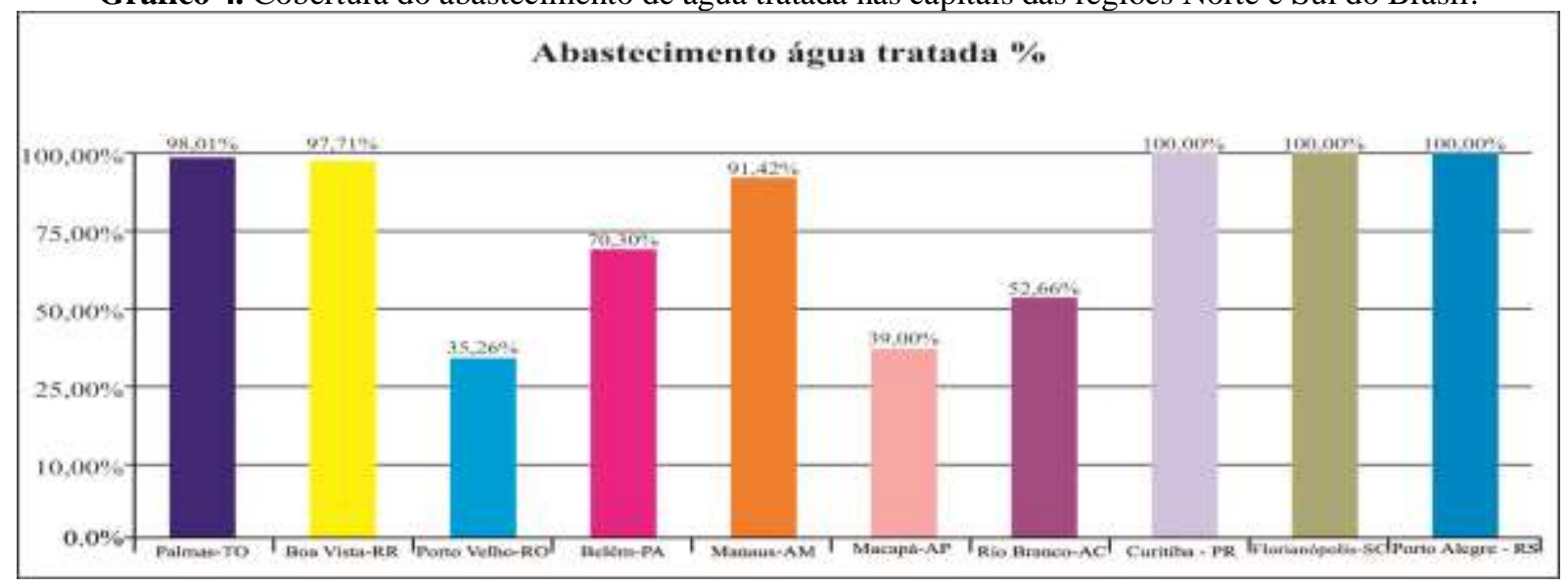

Fonte: Ministério do Desenvolvimento Regional - MDR (2020). Dados: SNIS (2018); Trata Brasil (2020).

De acordo com o gráfico acima, pode-se inferir que no quesito abastecimento de água tratada, as capitais da Região Norte, Palmas/TO e Boa Vista/RR e Manaus/AM, apresentam os maiores índices, ou seja, atendendo quase a totalidade da população, por outro lado, na Região Sul, Curitiba/PR, Florianópolis/SC, e Porto Alegre/RS, se destacam atendendo 100\% a população com estes serviços públicos.

Diante do exposto, a seguir serão apresentados os confirmados de pessoas contaminadas com o Covid-19, nas cidades de Palmas/TO; Boa Vista/RR; Porto Velho/RO; Belém/PA; Manaus/AM; Macapá/AP; Rio Branco/AC; Curitiba/PR; Florianópolis/SC; Porto Alegre/RS, nos messes de março a junho de 2020. 
Gráfico 5. Casos confirmados da Covid-19, nas capitais da Região Norte e Sul no mês de março de 2020.

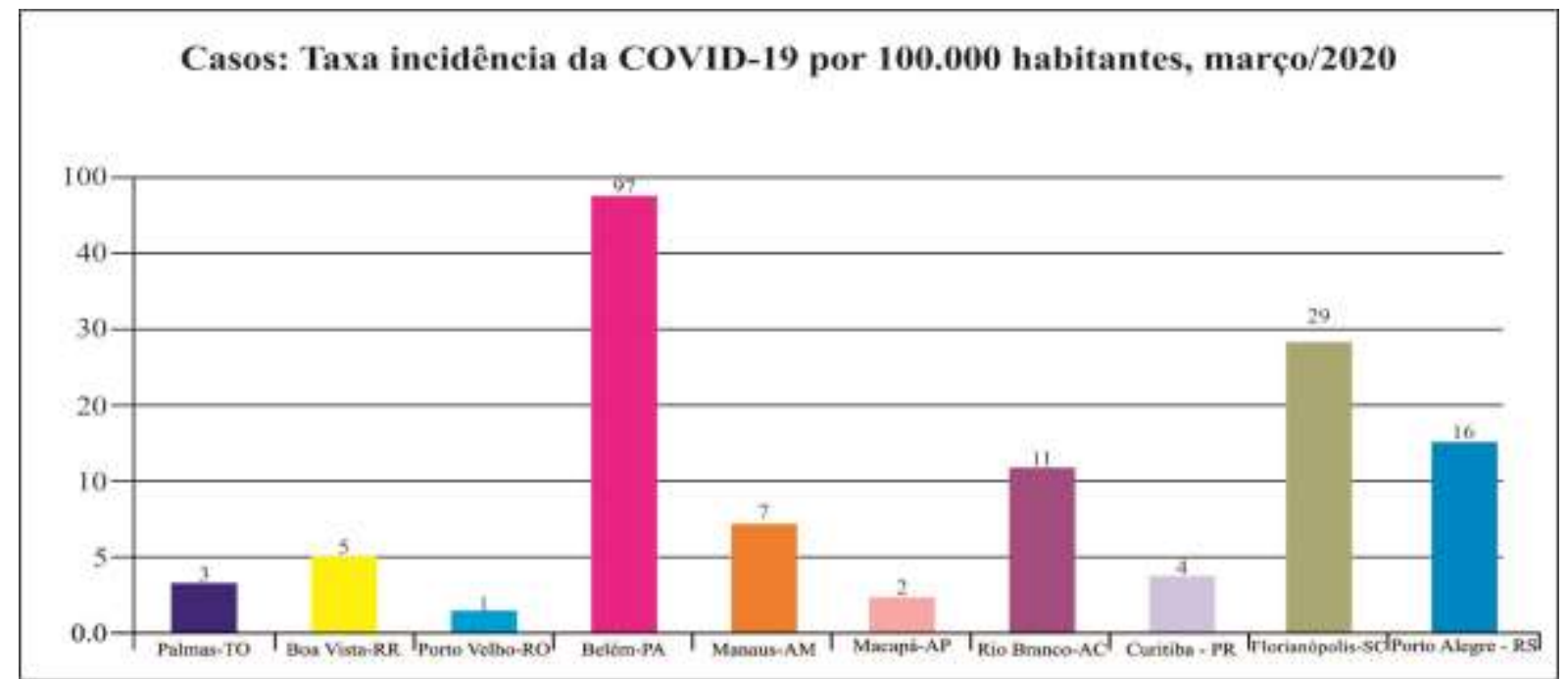

Fonte: Palmas (2020); Porto Velho (2020); Belém, (2020); Manaus (2020); Acre (2020); Boa Vista (2020); Macapá (2020); Paraná (2020); Florianópolis (2020); Porto Alegre (2020).

Conforme destaca o gráfico acima, observa-se que o maior número de casos confirmados da Covid-19, nas capitais da Região Norte, no mês de março, ocorreu em Belém/PA, já na Região Sul Porto Alegre/RS, é a capital que apresenta mais pessoas contaminadas.

Gráfico 6. Casos confirmados da COVID-19, nas capitais da Região Norte e Sul no mês de abril de 2020.

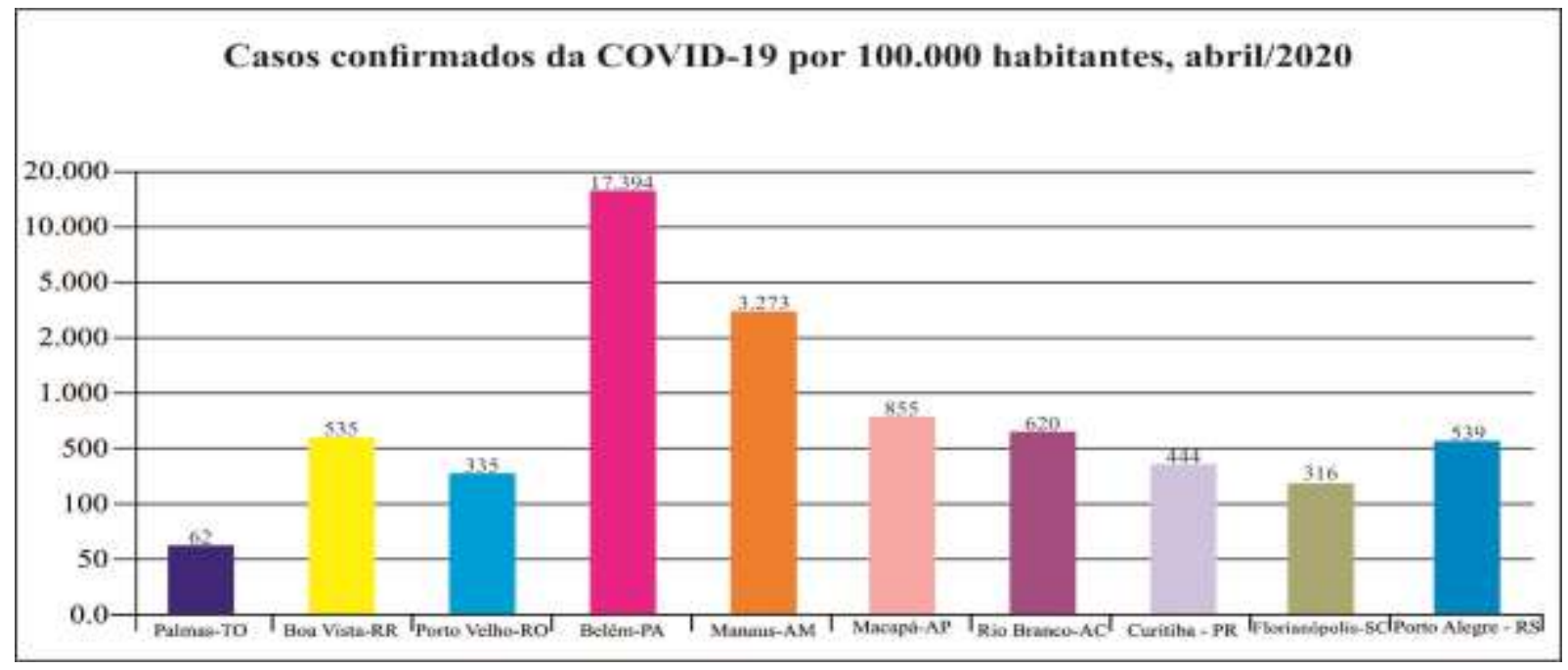

Fonte: Palmas (2020); Porto Velho (2020); Belém, (2020); Manaus (2020); Acre (2020); Boa Vista (2020); Macapá (2020); Paraná (2020); Florianópolis (2020); Porto Alegre (2020).

De acordo com gráfico acima, observa-se que no mês de abril na Região Norte as capitais que registraram o maior número de casos confirmados da Covid-19, foi Belém/PA, Boa Vista/RR, Manaus, Amazonas, Macapá, Amapá e Rio Branco, Acre. Por outro lado, na Região Sul, Porto Alegre/RS, Curitiba/PR e Florianópolis/SC, apresentam maiores índices de pessoas contaminadas. 
Gráfico 7. Casos confirmados da Covid-19, nas capitais da Região Norte e Sul no mês de maio de 2020.

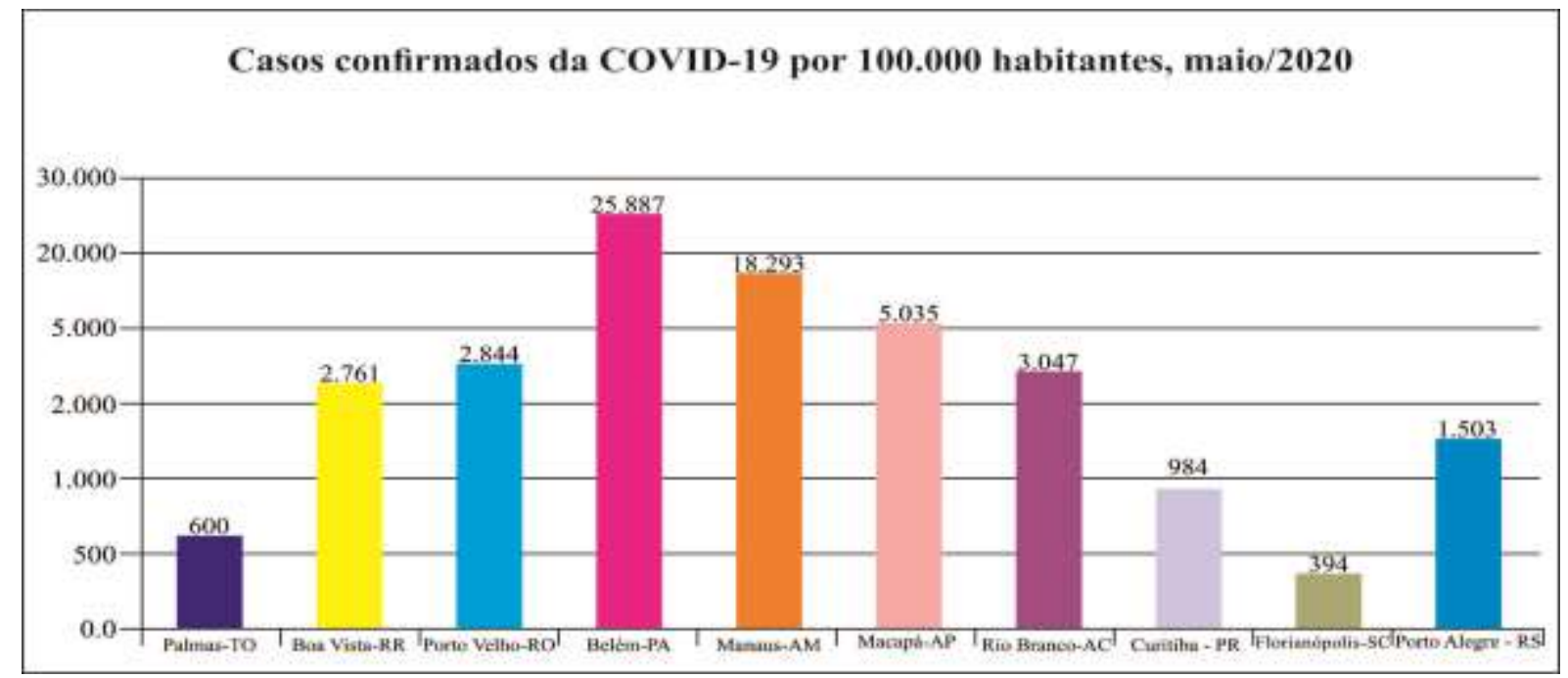

Fonte: Palmas (2020); Porto Velho (2020); Belém, (2020); Manaus (2020); Acre (2020); Boa Vista (2020); Macapá (2020); Paraná (2020); Florianópolis (2020); Porto Alegre (2020).

Conforme o gráfico acima pode-se observar que, no mês de maio na Região Norte, todas as capitais apresentaram altos índices de casos confirmados da Covid-19, com destaque para Belém/PA e Manaus/AM e Macapá/AP que passaram a liderar o ranking. Por outro lado, na Região Sul, todas as capitais aumentaram o número de casos, com destaque para Porto Alegre/RS, que apresenta maiores índices de pessoas contaminadas.

Gráfico 8. Casos confirmados da Covid-19, nas capitais da Região Norte e Sul no mês de junho de 2020.

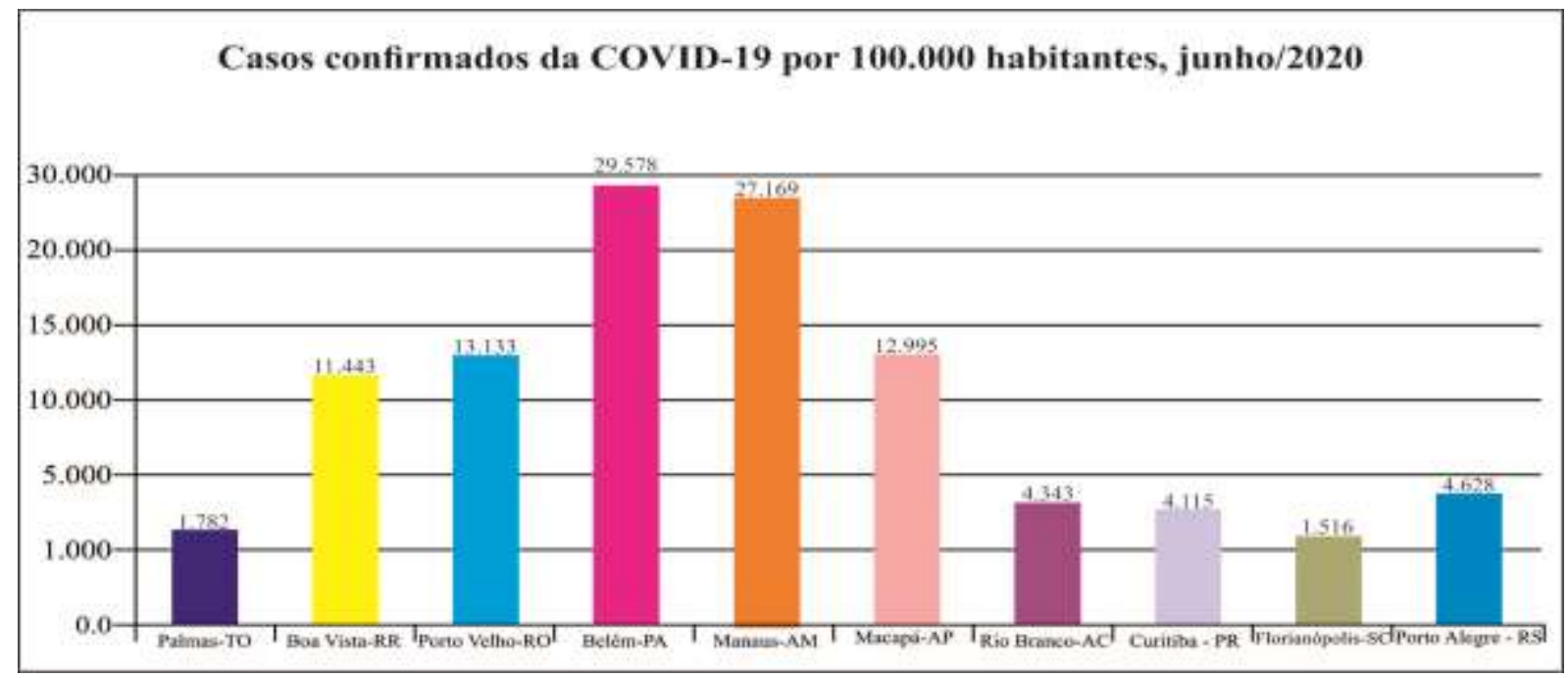

Fonte: Palmas (2020); Porto Velho (2020); Belém, (2020); Manaus (2020); Acre (2020); Boa Vista (2020); Macapá (2020); Paraná (2020); Florianópolis (2020); Porto Alegre (2020).

De acordo com gráfico acima, pode-se inferir que no mês de junho na Região Norte, todas as capitais apresentaram altos índices de casos confirmados da Covid-19, com destaque para Manaus/AM que passou a liderar o ranking. Por outro lado, na Região Sul, todas as capitais aumentaram o número de casos, com destaque para Porto Alegre/RS, que apresenta maiores índices de pessoas contaminadas.

Posto isto, a seguir serão apresentados os dados quantitativos das incidências dos casos confirmados nos messes de março a junho de 2020 . 
Gráfico 9. Incidência de casos confirmados da Covid-19, nas capitais da Região Norte e Sul no mês de março de 2020.

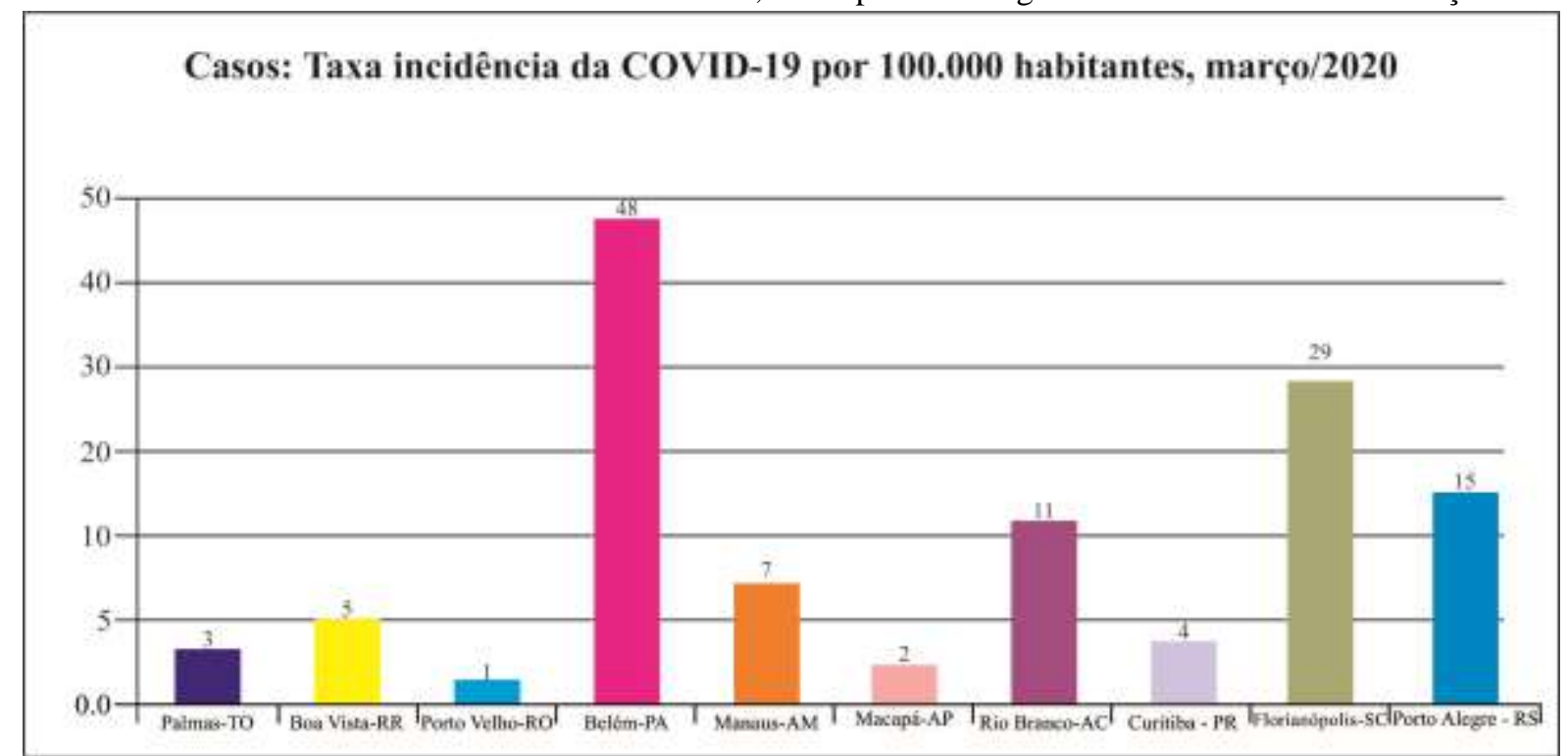

Fonte: Palmas (2020); Porto Velho (2020); Belém, (2020); Manaus (2020); Acre (2020); Boa Vista (2020); Macapá (2020); Paraná (2020); Florianópolis (2020); Porto Alegre (2020).

Conforme o gráfico acima, no que se refere à taxa de incidência de casos confirmados da Covid-19, nas capitais da Região Norte no mês de março, apresenta-se como destaque Belém/PA. Por outro lado, na Região Sul a maior taxa de incidência pertence a Florianópolis/SC.

Gráfico 10. Incidência de casos confirmados da COVID-19, nas capitais da Região Norte e Sul no mês de abril de 2020.

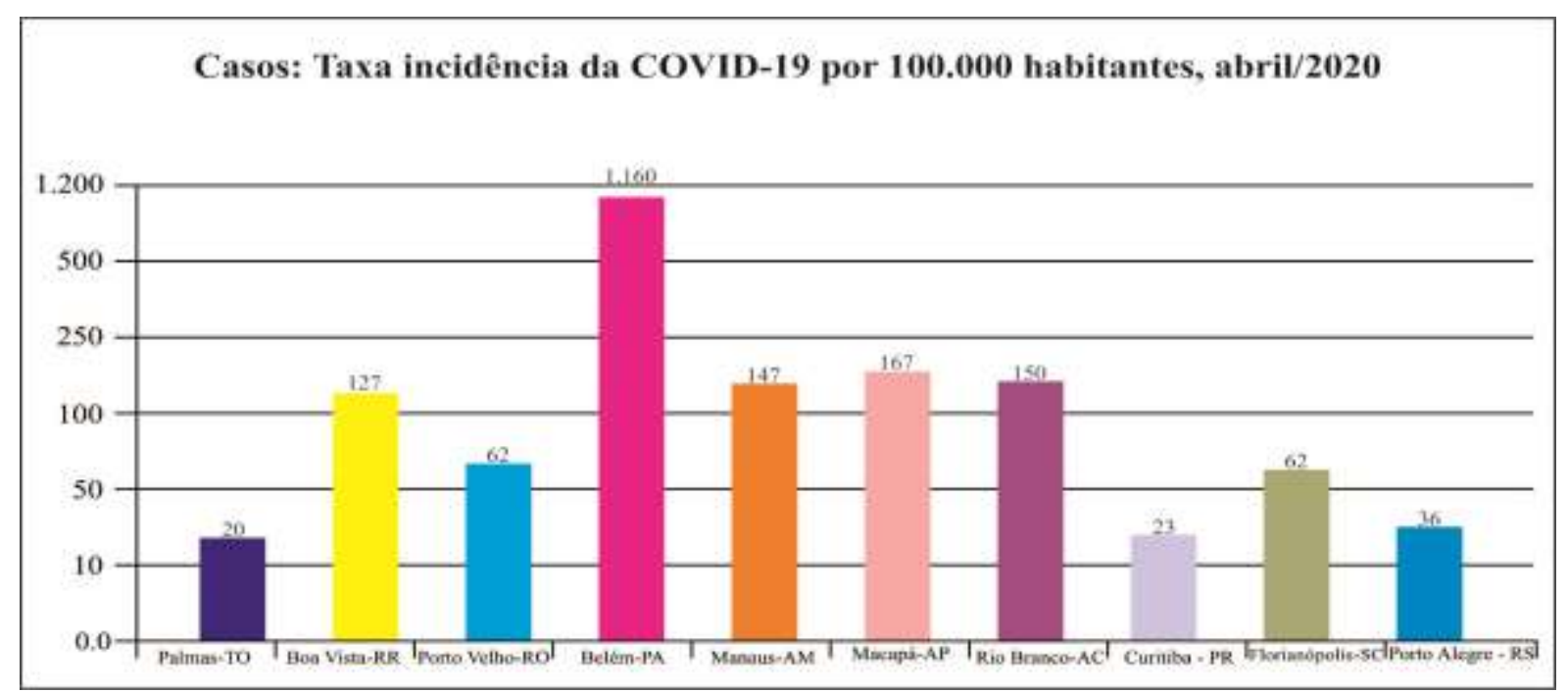

Fonte: Palmas (2020); Porto Velho (2020); Belém, (2020); Manaus (2020); Acre (2020); Boa Vista (2020); Macapá (2020); Paraná (2020); Florianópolis (2020); Porto Alegre (2020).

De acordo o gráfico acima, à taxa de incidência de casos confirmados da COVID-19, nas capitais da Região Norte no mês de abril, apresenta-se como destaque Belém/PA. Por outro lado, na Região Sul a maior taxa de incidência pertence a Florianópolis/SC. 
Gráfico 11. Incidência de casos confirmados da Covid-19, nas capitais da Região Norte e Sul no mês de maio de 2020.

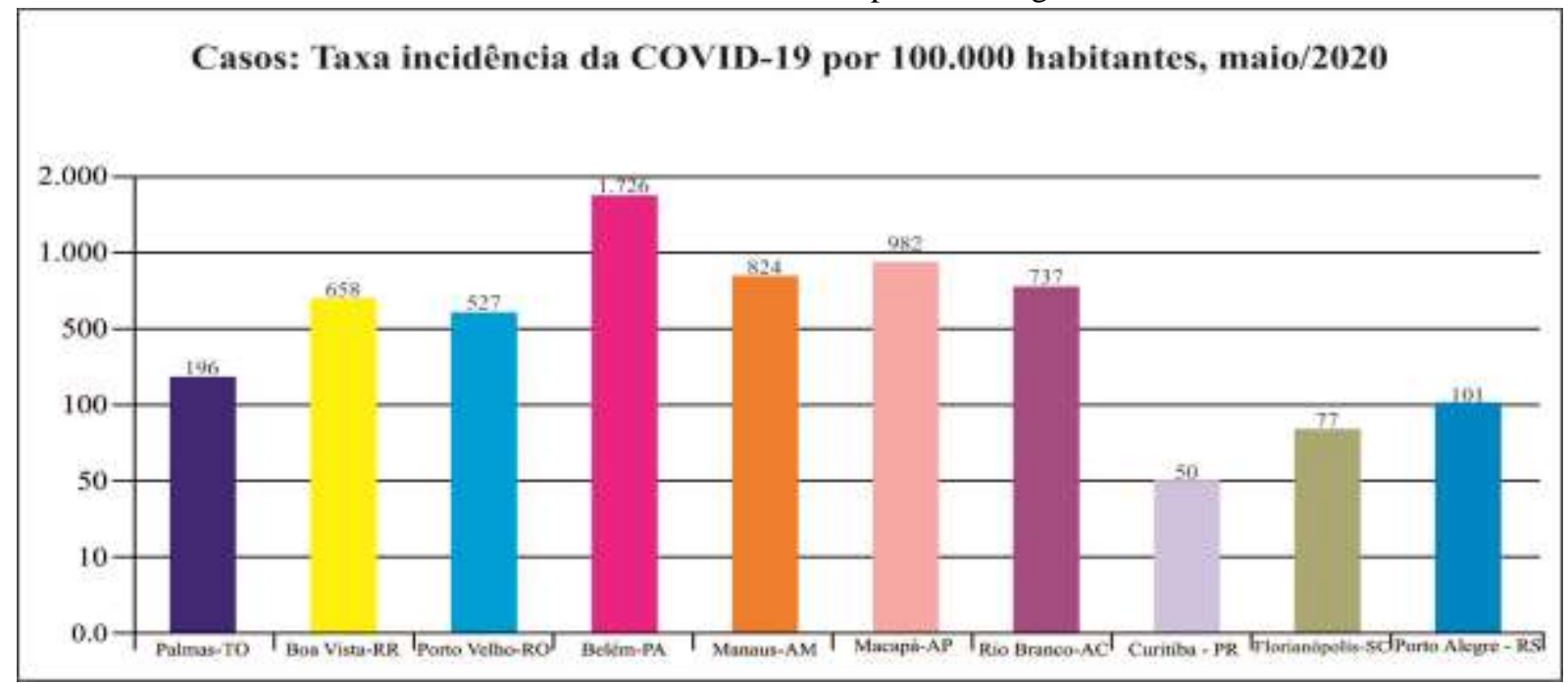

Fonte: Palmas (2020); Porto Velho (2020); Belém, (2020); Manaus (2020); Acre (2020); Boa Vista (2020); Macapá (2020); Paraná (2020); Florianópolis (2020); Porto Alegre (2020).

Conforme evidencia o gráfico acima, à taxa de incidência de casos confirmados da Covid-19, nas capitais da Região Norte no mês de maio, houve um crescimento considerável em todas as capitais, apresenta-se como destaque Belém/PA. Por outro lado, na Região Sul a maior taxa de incidência pertence a Florianópolis/SC que lidera o ranking.

Gráfico 12. Incidência de casos confirmados da Covid-19, nas capitais da Região Norte e Sul no mês de junho de 2020.

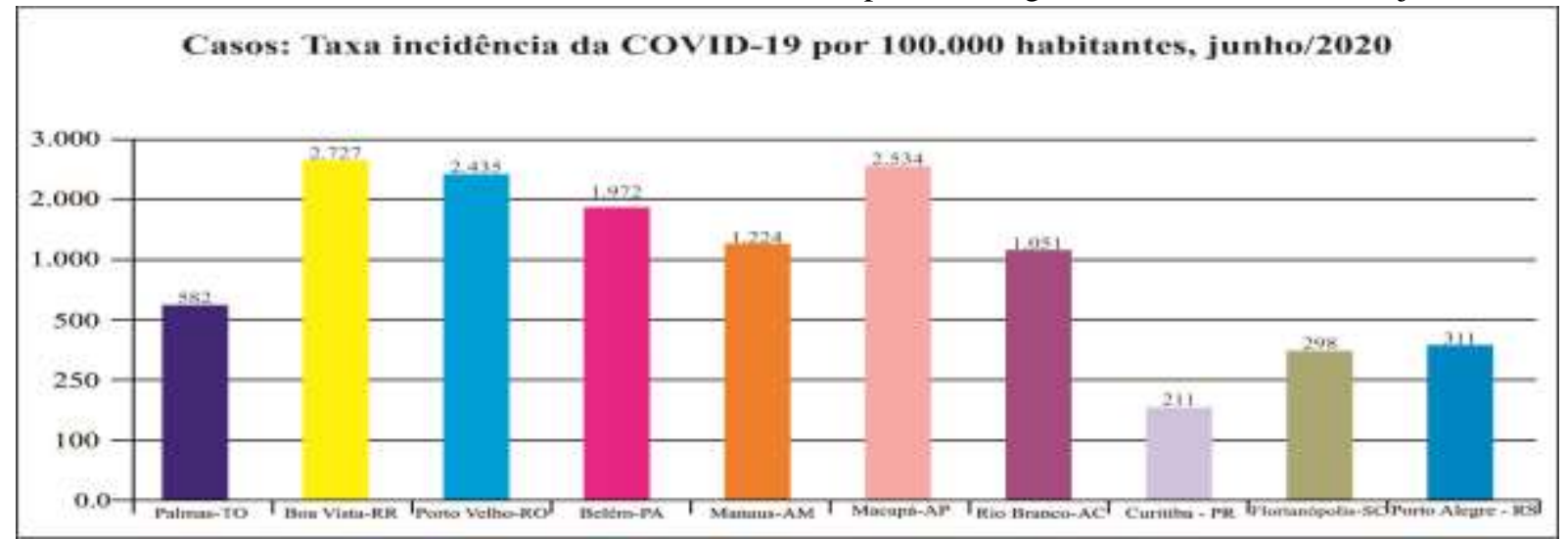

Fonte: Palmas (2020); Porto Velho (2020); Belém, (2020); Manaus (2020); Acre (2020); Boa Vista (2020); Macapá (2020); Paraná (2020); Florianópolis (2020); Porto Alegre (2020).

Conforme evidencia o gráfico acima, à taxa de incidência de casos confirmados da Covid-19, nas capitais da Região Norte no mês de junho, houve um crescimento considerável em todas as capitais, apresenta-se como Boa Vista/RR, Porto Velho/RO e Macapá/AP que passaram liderar o ranking. Por outro lado, na Região Sul as maiores taxas de incidência foram registradas em Florianópolis/SC e Porto Alegre/RS. 
Quadro 5. Opiniões de instituições e especialista sobre as possíveis causas de disseminação do SARS-CoV-2 (Covid-19), nos meses de março e abril/2020.

\begin{tabular}{|c|c|c|c|}
\hline Portal & Data & Nome & Título ou atuação \\
\hline \multirow[b]{2}{*}{ FIOCRUZ } & \multirow[b]{2}{*}{09 de março. } & Estevão Portela Nunes & $\begin{array}{l}\text { Médico infectologista e vice-diretor de } \\
\text { Serviços Clínicos do INI/Fiocruz. }\end{array}$ \\
\hline & & \multicolumn{2}{|c|}{$\begin{array}{l}\text { Opinião apresentada: "O Covid-19 é transmitido a partir de gotículas que } \\
\text { tem que chegar de uma pessoa para outra. A pessoa tosse, expectora, às vezes } \\
\text { a mão dela fica infectada com essas gotículas e transmite o vírus através do } \\
\text { contato. Por isso a lavagem das mãos é um dos aspectos mais importantes } \\
\text { para combater o surto de coronavírus". }\end{array}$} \\
\hline \multirow[b]{2}{*}{ BandNews FM } & \multirow[b]{2}{*}{31 de março. } & Édison Carlos & Presidente do Instituto Trata Brasil \\
\hline & & \multicolumn{2}{|c|}{$\begin{array}{l}\text { Opinião apresentada: A falta de saneamento básico contribui para } \\
\text { propagação da Covid-19. A carência desses serviços pode deixar a população } \\
\text { vulnerável, fazendo com que as pessoas adoeçam com mais frequência. }\end{array}$} \\
\hline \multirow[b]{2}{*}{$\begin{array}{l}\text { BBC News } \\
\text { Brasil }\end{array}$} & \multirow[b]{2}{*}{02 de abril } & Juliana Calabria de Araújo & $\begin{array}{l}\text { Doutora em Engenharia Hidráulica e } \\
\text { Saneamento da UFMG e subcoordenadora do } \\
\text { INCT - ETS Sustentáveis. }\end{array}$ \\
\hline & & \multicolumn{2}{|c|}{$\begin{array}{l}\text { Opinião apresentada: O esgoto pode ser via de contágio do novo } \\
\text { coronavírus, "[...] embora o conhecimento sobre a viabilidade (capacidade de } \\
\text { infectar) do novo coronavírus seja limitado, ele poderia estar viável por vários } \\
\text { dias, levando à transmissão fecal-oral, conforme verificado nos casos de } \\
\text { outros vírus, que transmitem a síndrome respiratória aguda (CoV) e a } \\
\text { síndrome respiratória aguda do Oriente Médio (CoV.2)". }\end{array}$} \\
\hline
\end{tabular}

Fonte: Fiocruz (2020); BandNews FM (2020); BBC News Brasil (2020). 
Quadro 6. Opiniões de instituições e especialista sobre as possíveis causas de disseminação do SARS-CoV-2 (Covid-19), nos meses de maio e junho/2020.

\begin{tabular}{|c|c|c|c|}
\hline Portal & Data & Nome & Título ou atuação \\
\hline \multirow[b]{2}{*}{ Uol Notícias } & \multirow[b]{2}{*}{28 de maio. } & $\begin{array}{l}\text { Centro de Controle e } \\
\text { Prevenção de Doenças dos } \\
\text { Estados } \\
\text { Unidos (CDC) }\end{array}$ & $\begin{array}{l}\text { Agência do Departamento de Saúde e } \\
\text { Serviços Humanos dos Estados Unidos }\end{array}$ \\
\hline & & \multicolumn{2}{|c|}{$\begin{array}{l}\text { Opinião apresentada: "Pode ser possível que uma pessoa adquira a covid- } \\
19 \text { tocando em uma superfície ou objeto com o vírus e, em seguida, tocando } \\
\text { sua própria boca, nariz ou possivelmente seus olhos. Não se acredita que } \\
\text { essa seja a principal maneira de o vírus se espalhar [...]." }\end{array}$} \\
\hline \multirow[b]{2}{*}{ CNN Brasil } & \multirow[b]{2}{*}{09 de junho. } & Maria Van Kerkhove & $\begin{array}{c}\text { Infectologista e líder técnica da Organização } \\
\text { Mundial de Saúde (OMS) }\end{array}$ \\
\hline & & \multicolumn{2}{|c|}{$\begin{array}{l}\text { Opinião apresentada: O novo coronavírus, um patógeno respiratório, } \\
\text { "Passa de um indivíduo através de gotículas infecciosas", liberadas quando } \\
\text { alguém tosse ou espirra. }\end{array}$} \\
\hline & & $\begin{array}{l}\text { Larissa Mies Bombard e } \\
\text { Pablo Luiz Maia } \\
\text { Nepomuceno }\end{array}$ & $\begin{array}{l}\text { Departamento de Geografia da Faculdade de } \\
\text { Filosofia, Letras e Ciências Humanas } \\
\text { (FFLCH) da USP }\end{array}$ \\
\hline Jornal da USP & 18 de junho. & \multicolumn{2}{|c|}{$\begin{array}{l}\text { Opinião apresentada: Segundo pesquisas desenvolvidas, foi detectado a } \\
\text { presença do novo coronavírus nos excrementos humanos, mesmo em casos } \\
\text { assintomáticos ou curados, portanto, sua relação com a proliferação no } \\
\text { número de infectados. "[...] o vírus continua sendo secretado pelas fezes } \\
\text { mesmo após a pessoa ter sido curada e mesmo em pessoas que estão } \\
\text { assintomáticas, porque pode sim acontecer algo que é chamada de } \\
\text { contaminação fecal-oral, ou seja, as pessoas ingerirem o vírus por meio das } \\
\text { fezes". }\end{array}$} \\
\hline
\end{tabular}

Fonte: Portal Uol Notícias (2020); CNN Brasil (2020); Jornal da USP (2020).

\subsection{Discussão dos resultados}

Analisando esses resultados à luz das variáveis relacionada à cobertura da rede de esgoto e água tratada; incidência de casos confirmados da Covid-19, nas capitais das regiões Norte e Sul do Brasil, além das opiniões de instituições e especialista sobre as possíveis causas de disseminação do novo coronavírus.

No que se referem à coleta de esgoto pode-se inferir que, a Região Sul, especificamente as capitais Curitiba e Porto Alegre, se destacam com a maior cobertura destes serviços públicos com o atendimento de $90 \%$ de suas populações, no entanto, Florianópolis, tende somente $64 \%$ de seus habitantes. Fica evidente que, mesmo que estas capitais sejam pertencentes aos estados que apresentam melhores índices de desenvolvimento, não atendem a totalidade de seus habitantes com estes serviços essenciais. Por outro lado, na Região Norte, capitais Palmas, Boa Vista, apresentam os melhores índices de cobertura com o atendimento de $85 \%$ e $73 \%$ de seus habitantes. Esses índices podem estar diretamente relacionados à condição de ambas possuírem um plano urbanístico planejado, fator que permite o crescimento relativamente ordenado.

No tocante ao tratamento de esgoto, pode-se observar que, as capitais da Região Norte, Boa Vista, 73\% e Palmas, $66 \%$ de suas populações são atendidas, apresentam os melhores índices. Esses indicadores positivos podem ser caracterizados 
como resultados de políticas de saneamento implementadas nas últimas décadas, provocadas pelo processo de controle da expansão territorial. Na Região Sul, Curitiba se destaca com a maior cobertura destes serviços públicos, atendendo 94,7\% de seus moradores. Esse fator deve estar relacionado ao fato de Curitiba ser uma referência na implementação de políticas públicas de sustentabilidade urbana e meio ambiente. Todavia, Florianópolis e Porto Alegre, apresentam o mesmo desempenho nesse quesito, ambas aproximam de 50\% de atendimento de suas populações com o acesso ao tratamento de esgoto. Esse fenômeno pode estar diretamente ligado ao crescimento desordenado, ou seja, o surgimento de bairros sem condições mínimas de infraestrutura, habitação e, sobretudo, sem coleta e tratamento de esgoto.

No quesito abastecimento de água tratada, pode-se notar que, as capitais da Região Norte, Palmas e Boa Vista e Manaus, apresentam os maiores índices, ou seja, superiores á 90\% de cobertura. Por outro lado, na Região Sul, Curitiba, Florianópolis e Porto Alegre, se destacam com o atendendo 100\% de seus moradores com estes serviços públicos. Certamente, esses resultados positivos estão relacionados à ocorrência da terceirização dos serviços de abastecimento de água tratada nestas capitais, através de concessões ou parcerias público—- privada.

Com relação às incidências de casos confirmados da Covid-19, pode-se observar que, no mês de março, apresenta-se como destaque da Região Norte a cidade de Belém, com 48 casos por (100 mil habitantes). No mês de maio Belém, saltou para 1.726 casos, fechando o mês de junho com 1.972 testes positivos por (100 mil moradores). Ou seja, entre os meses de março a junho, houve um aumento de $4.108 \%$ da taxa de incidência. Outra variável que chama atenção é o crescimento acelerados do número de casos em Boa Vista, Porto Velho, Manaus, Macapá e Rio Branco, nos messes de maio e junho. Todavia, o destaque ficou para Boa Vista, que saltou de (5) cinco casos confirmados por (100 mil habitantes), no mês de março para $2.727 \mathrm{em}$ junho, registrando o aumento de $54.540 \%$ em 120 dias. Importa ressaltar ainda que, a cidade de Palmas, apresentou o menor índice de pessoas infectadas 100 mil habitantes, com (3) três casos confirmados em março, saltando para 582 em junho, com a taxa de crescimento de $19.400 \%$.

De outra forma, a Região Sul, Florianópolis, e Porto Alegre, se posicionaram na linha de frente no tocante ao quantitativo de pessoas contaminadas por (100 mil habitantes). Florianópolis, no mês de março somou 29 casos confirmados chegando o mês de junho com 298 pessoas infectadas, evolução de aproximadamente 1.027,\%. Já Porto Alegre, em março apresentou 15 casos, saltando para 311 em junho, um acréscimo de $2.073 \%$ em quatro meses. Sobretudo, é importante destacar que, Curitiba apresentou a menor taxa de casos confirmados por (100 mil habitantes), nesse período, pode-se observar que, de março a maio, registrou-se 77 testes positivos. No entanto, no mês de junho, foram registrados 211 casos, ou seja, em 30 dias houve um aumento de $274,025 \%$ de pessoas infectadas.

Em síntese, conforme foi evidenciado nos resultados deste trabalho pode-se observar uma notável coincidência inerente o aumento de número de casos de pessoas contaminadas pelo novo coronavírus, nas capitais que apresentam baixa cobertura de atendimentos de seus habitantes com os serviços de coleta, tratamento de esgoto e água tratada. No caso de Belém e Manaus, por exemplo, que somente 13,56\% e, 12,43\% de seus habitantes são atendidos com os serviços de coleta de esgoto. No que se refere ao tratamento de esgoto, Belém atende apenas 2,33\% de seus moradores e Manaus, 12,43\%. Por outro lado, as capitais que Palmas, Curitiba, Florianópolis e Porto Alegre, que apresentam bons indicadores nesse quesito, obtiveram as menores taxas de contaminação por (100 mil habitantes). Esses dados corroboram com as opiniões das instituições e especialista que afirmam que a principal causa da disseminação do novo coronavírus é a falta de saneamento básico, situação peculiar da maioria das cidades brasileiras.

\section{Considerações Finais}


Os efeitos da pandemia do novo coronavírus provocaram mudanças comportamentais, entre os seres humanos, permitindo a retomada da discussão de antigos problemas relacionados às disparidades regionais e ausência de políticas públicas essências e preponderantes para a qualidade de vida da população brasileira. Diante disso, objetivo inicial que foi o de analisar a relação das incidências de casos de pessoas infectadas pelo novo coronavírus no período de 15 de março a 30 de junho de 2020, com a falta de políticas públicas de saneamento básico nas capitais das regiões Sul e Norte do Brasil. Para atingir esse objetivo, recorreu-se a fundamentação teórica, nesse universo, identificou-se um arcabouço de evidências textuais, conceitos, abordagens históricas e leis que discorrem sobre a temática das políticas públicas de saneamento básico no Brasil.

Além disso, foram identificados e selecionados três relatórios técnicos que descrevem a situação das políticas públicas de saneamento no Brasil, o primeiro na base de dados do Ministério do Desenvolvimento Regional, o Diagnóstico dos Serviços de Água e Esgoto do Sistema Nacional de Informações sobre Saneamento. O segundo, assim como o terceiro, respectivamente, na plataforma do site, do Instituto Trata Brasil, o relatório descritivo do ranking do saneamento e o Manual do Saneamento Básico, indicadores de cobertura, tratamento de água e esgoto nas capitais das regiões Norte e Sul do Brasil. Ambos mostrando que os baixos índices dos serviços de saneamento no território brasileiro obedece á lógica das desigualdades regionais, a Região Norte, apresenta os piores indicadores de investimentos em políticas públicas deste setor. Dessa forma, é necessário concentrar os esforços e a cobrança aos agentes políticos por implementação de programas que visam universalização do acesso á coleta, tratamento do esgoto e água tratada.

Para identificação dos casos confirmados da Covid-19, foram selecionados os sites das secretarias de saúde das capitais da Região Norte e Sul. Assim, foi realizado o monitoramento semanalmente da evolução dos casos confirmados a partir da divulgação oficial pelas secretarias de saúde de cada estado, no período de março a 30 de junho. Com as informações em mãos, procedeu-se a compilação dos dados e a sistematização em gráficos com a descrição das incidências de casos confirmados da Covid-19, por (100 mil habitantes). Por fim, foram identificados seis portais de notícias com matérias publicadas com ênfase nas opiniões de especialistas que defendem a tese que uma das principais causas da proliferação do coronavírus no Brasil, está diretamente relacionada, a não universalização de políticas públicas de saneamento básico.

Portanto, com o término deste trabalho, foi possível identificar elementos que podem ser aprofundados em investigações futuras. Nesse sentido, recomenda-se que sejam executadas pesquisas científicas e trabalhos acadêmicos, para analisar com maior profundidade as variáveis que podem ser determinantes para o aumento de casos de pessoas infectadas pelo novo coronavírus em outras regiões do Brasil.

\section{Referências}

Alencar, E. (2002). Análise do significado: roteiro de aula. 20 f. Mimeo.

Aguilar, L. F. (2012). Política Pública. México: Siglo XXI Editores, 2012.

Acre (2020) Secretária Estadual de Saúde do Acre. Monitoramento de notificações. http://covid19.ac.gov.br/monitoramento/notificacoes/esus.

Bardin, I. (2010). Análise de conteúdo. Lisboa: Edições Setenta, 226 p.

Belém (2020). Secretaria Municipal de Saúde de Belém. Transparência Covid-19. Monitoramento dos casos. Recuperado de http://contratoemergencial.belem.pa.gov.br.

Borja, P. C. (2014). Política pública de saneamento básico: uma análise da recente experiência brasileira: Recuperado de https://www.scielosp.org/article, Revista, Saúde Soc. São Paulo, 23(2), 432-447.

Borja, P. C. (2004). Política de saneamento: instituições financeiras internacionais e mega-programas: um olhar através do Programa Bahia Azul. Tese (Doutorado em Urbanismo) - Faculdade de Arquitetura e Urbanismo da Universidade Federal da Bahia, Salvador, 2004. Recuperado de https://repositorio.ufba.br.

BandNews FM (2020). Cobertura especial ao programa Duas a Dois. (Édison Carlos, Presidente do Instituto Trata Brasil). https://bandnewsfm.band.uol.com.br. 
BBC News Brasil (2020). O que fazer para evitar ser infectado pelo coronavírus em diferentes situações. (Juliana Calabria de Araújo, Doutora em Engenharia Hidráulica e Saneamento da UFMG). https://www.bbc.com/portuguese/geral.

Constituição da república Federativo do Brasil de (1988). Brasília, DF, Senado Federal, Secretaria especial de editoração e publicações subsecretaria de edições técnicas abril / 2016.

CNN Brasil (2020). Novo coronavírus pode permanecer em superfícies por três dias, diz estudo. (Maria Van Kerkhove, Infectologista e líder técnica da Organização Mundial de Saúde (OMS) https://www.cnnbrasil.com.br/saude/2020/03/19/novo-coronavirus.

Flick, U. (2013). Introdução à pesquisa qualitativa. Tradução Joice Elias Costa. (3a ed.), Artemed.

Florianópolis (2020) Secretária Municipal de Saúde de Florianópolis. https://covidometrofloripa.com.br.

INCT: Etes-Sustentaveis. (2020). História do Saneamento Básico no Brasil. https:// www.etes-sustentaveis.org.

IBGE (2020). Instituto Brasileiro de Geografia e Estatística. Cidades e Estados do Brasil. https://cidades.ibge.gov.br.

Jornal da USP (2020). Saneamento básico precário facilita proliferação da Covid-19 no Brasil. (Larissa Mies Bombard e Pablo Luiz Maia Nepomuceno, Departamento de Geografia da Faculdade de Filosofia, Letras e Ciências Humanas (FFLCH) da USP) https://jornal.usp.br/atualidades/saneamento-basico.

Lei no 9.984, de 17 de julho de (2000). Dispõe sobre a criação da Agência Nacional de Águas e Saneamento Básico (ANA). http://www.planalto.gov.br/ccivil.

Lei $\mathrm{n}^{\circ} 11.445$, de 5 de janeiro de (2007). Estabelece as diretrizes nacionais para o saneamento básico; cria o Comitê Interministerial de Saneamento Básico. http://www.planalto.gov.br/ccivil

Lei $\mathrm{n}^{\circ} 14.026$ de 15 de julho de (2020). QUE atualiza o marco legal do saneamento e altera a Lei $n^{\circ} 9.984$, de 17 de julho de 2000. http://www.planalto.gov.br/ccivil.

Macapá (2020). Prefeitura Municipal de Macapa. Secretaria Municipal de Saúde. Portal da transparência da Prefeitura municipal de Macapá. https://transparencia2.macapa.ap.gov.br.

Ministério do Desenvolvimento Regional (2020). Diagnóstico dos Serviços de Água e Esgoto - 2018. Sistema Nacional de Informações sobre Saneamento 2018. http://snis.gov.br/diagnostico-anual-agua-e-esgotos/diagnostico-dos-servicos-de-agua-e-esgotos-2018.

Ministério da Saúde (2020). Secretaria em Vigilância em Saúde-Ministério da Saúde: Centro de Operações de Emergências em Saúde Pública| COE-nCoV. http://portalarquivos2.saude.gov.br.

Manaus (2020) Secretaria Municipal de Saúde de Manaus. Relatório Covid-19 Manaus. https://covid19.manaus.am.gov.br/monitoramento.

Palmas/TO (2020). Secretaria Municipal de Saúde de Palmas/TO. Boletim Epistemológico Coronavírus (COVID-19). Centro de operações de emergência em saúde. https://coronavirus.palmas.to.gov.br/boletim.

Paraná (2020). Governo do Estado do Paraná. Secretária de Saúde. Gerenciador de Ambiente Laboratorial. http://www.saude.pr.gov.br/Pagina/CoronavirusCOVID-19.

Porto Velho (2020). Secretaria Municipal de Saúde de Porto Velho. Vigilância em Saúde. Painel Covid Radar. https://painel.covidradar.org.br.

Popper, K. (2008). A lógica da pesquisa científica. Tradução de Leônidas Hegenberg e Octanny Silveira da Mota. (16a ed.), Cultrix.

Porto Alegre (2020). Secretaria Municipal de Saúde de Porto Alegre. Recuperado de Covid-19. https://prefeitura.poa.br/coronavirus.

Portal Fiocruz (2020). Fiocruz divulga resultados de proejto para vigilância do coronavírus em esgoto. (Estevão Portela Nunes). ttps://portal.fiocruz.br/noticia.

Portal UOL Notícias (2020). Coronavírus no esgoto revela deficiências do saneamento brasileiro. Centro de Controle e Prevenção de Doenças. Estados Unidos (CDC). https://noticias.uol.com.br.

Rodrigues, M. M. A. (2010). Políticas públicas. Publifolha, 2010.94p.

Rocha, A, A. (2016). Histórias do Saneamento. Editora Blucher, Brasil.

Roraima (2020). Governo do Estado de Roraima. Secretaria de Estado DE SAÚDE. Boletim epidemiológico sobre a doença pelo Coronavírus (COVID-19). https://www.saude.rr.gov.br/index.php/informacoesx/coronavirus/informacoes-coronavirus

Secchi, L. (2013). Políticas públicas conceitos, esquemas de análise, casos práticos. (2a ed.), Cengage Learning, 2013. 168p.

Saraiva, E. \& FerrarezI, E. (2006). Políticas públicas. Brasília: Enap, 2006.

Trata Brasil. (2012). Manual do Saneamento Básico: Entendendo o saneamento básico ambiental no Brasil e sua importância socioeconômica. https://www.tratabrasil.org.br.

Trata Brasil. (2020). Ranking do Saneamento Básico. http://www.tratabrasil.org.br.

Teixeira, E, C. (2014). O papel das políticas públicas no desenvolvimento local e na transformação da realidade. http//www.dhnet.org.br.

Teixeira, E, C. (2002). O papel das políticas públicas no desenvolvimento local e na transformação da realidade. http://www.dhnet.org.br. 
Research, Society and Development, v. 10, n. 2, e11810211755, 2021 (CC BY 4.0) | ISSN 2525-3409 | DOI: http://dx.doi.org/10.33448/rsd-v10i2.11755

UFRGS (2020). Universidade Federal do Rio grande do Sul. Artigo: Coronavírus, Covid-19, SARSCoV-2 e outros - um ponto de vista virológico. https://www.ufrgs.br/coronavirus/base/artigo-coronavirus-covid-19. 